\title{
Planificación Y Preparación Para La Gestión Sustentable De Riesgos Y Crisis En El Turismo Mexicano. Estudio Piloto En Ciudad Juárez, Chihuahua
}

\author{
Dr. Manuel Ramón González Herrera. \\ Mtro. José Manuel Lerma Legarreta. \\ Universidad Autónoma de Ciudad Juárez. México
}

doi: 10.19044/esj.2016.v12n5p42 URL:http://dx.doi.org/10.19044/esj.2016.v12n5p42

\begin{abstract}
Tourism is a sector vulnerable to different types of risks and crises caused by multiple and diverse events, which occur in different space-time dimensions. The aim of the paper is to analyze -in Mexican tourism- the planning and preparation process for the sustainable and integrated management of risk and crisis and implementing them through participatory construction of crisis management plan caused by insecurity. A detailed literature review and analysis of regulations was conducted; also interviews with specialists, researchers, academic professionals and managers were developed; case analysis; systematization of secondary data; and group work with three focus groups, developed through a pilot study and in-depth interviews to fill information gaps. As result, the contextualization of the study object and the analysis of the institutional foundations for risk and crisis management is presented; according to such references, the plan for crisis management of tourism in Ciudad Juarez was built in a participatory way. For this purpose, the model of the 4 "R" was used, which is based on the case of crises caused by unsafe situations. It includes a justification, the situation assessment by social perception of the problem, and strategic projection based on the participatory integration of the components of tourism planning.
\end{abstract}

Keywords: Risk, crisis, tourism, management, sustainable, insecurity, planning

\section{Resumen}

El turismo es un sector vulnerable ante diferentes tipos de riesgos y crisis provocadas por eventos múltiples y diversos, los cuales acontecen en 
dimensiones espacio-temporales diferenciadas. Es objetivo del artículo fundamentar el proceso de planificación y preparación para la atención sustentable e integrada de riesgos y crisis en el turismo mexicano, e implementarlos mediante la construcción participativa de un plan de gestión de crisis provocadas por la inseguridad. Se realizó una detallada revisión documental y normativa; entrevistas con especialistas, investigadores, académicos y gestores; análisis de casos; sistematización de datos secundarios; y trabajo grupal mediante 3 grupos focales desarrollados a través de un estudio piloto, así como entrevistas en profundidad para cubrir vacíos de información. Como resultados se realiza la contextualización del objeto de estudio y un análisis de las bases institucionales para la gestión de riesgos y crisis; atendiendo a tales referentes se construyó de forma participativa el plan para la gestión de crisis en el turismo de Ciudad Juárez utilizando el modelo de las 4 "R" (Reducción- Preparación- RespuestaRecuperación) el cual está basado en el caso de las crisis provocadas por situaciones de inseguridad; incluye una justificación, el diagnóstico situacional según percepción social de la problemática, y la proyección estratégica fundamentada en la integración participativa de los componentes de la planificación turística.

Palabras clave: riesgo, crisis, turismo, gestión, sustentable, inseguridad, planificación

\section{Introducción}

El turismo es un sector muy vulnerable ante diferentes tipos de crisis provocadas por eventos de génesis múltiples y diversos grados de reforzamiento e intensidad, los cuales acontecen en dimensiones espaciotemporales diferenciadas. Estos eventos pueden tener efectos catastróficos y continuados para los destinos turísticos y sus organizaciones, así como sobre el resto de las actividades sociales y económicas que acontecen en el espacio geográfico que ocupan, con impactos de interés particular para las condiciones de bienestar y supervivencia de los residentes locales y de los visitantes que se encuentran en el destino al momento de generarse cualquier acontecimiento que pueda desatar una situación de crisis.

La problemática de estudio se enmarca en el hecho de que el mundo actual es más propenso a sufrir crisis y desastres debido a la presencia de varios factores, tales como el crecimiento de la población, el desarrollo espontáneo de las ciudades, la presión económica global, la degradación de la tierra, el deterioro ambiental, la presencia de la guerra como amenaza global y el impacto de las tecnologías (Faulkner, 1999, En: RodríguezToubes, 2011). En tal sentido, se ha registrado un "incremento catastrófico en el número de desastres causados por fenómenos naturales, los cuales se han 
más que duplicado desde 1980” (Cutter, et al, 2015: 278), factor que según el grupo de autores antes citados responde a eventos climatológicos (olas de calor, sequías, incendios forestales); hidrológicos (inundaciones, deslizamientos de tierra); meteorológicos (tormentas) y geofísicos (terremotos, tsunamis, volcanes) (Ibídem).

En este contexto, el Comité Consultivo Público Conjunto de la Comisión para la Cooperación Ambiental en América del Norte mediante un reciente comunicado de prensa hace un llamado urgente para "adoptar soluciones prácticas y respetuosas del medio ambiente para el manejo de las precipitaciones pluviales extraordinarias a través de soluciones sustentables para mitigar los efectos de las aguas pluviales” (CCPC-CCA, 2015). Señala que el "control de los caudales excesivos generados por la precipitación pluvial requiere el compromiso firme de los gobiernos y la sociedad civil para idear e instrumentar soluciones sustentables a tan generalizado problema", al tiempo que reconoce la necesidad de "propiciar la participación activa de las comunidades locales en la adopción de soluciones innovadoras, prácticas y sustentables en términos ambientales, así como sensibilizar y fomentar la participación ciudadana” y que el rol de los "responsables de la formulación de políticas consiste en evaluar con toda precisión cuán vulnerables son nuestras comunidades frente a los efectos perjudiciales de las precipitaciones pluviales extraordinarias” (Ibídem).

Ante esta compleja y amplia problemática se enuncia la siguiente interrogante de investigación con el propósito de encontrar alternativas explicativas que sirvan de base para la oportuna actuación: ¿Cómo promover la planificación y preparación sistemática e integrada del proceso de gestión sustentable de riesgos y crisis en el turismo mexicano?

El problema objeto de estudio asume como premisa la insuficiente integración entre el turismo y la gestión de riesgos y crisis (OMT, 2011), razón por la cual, y en consecuencia con la problemática enunciada se hace imprescindible la propuesta acertada de soluciones estratégicas con la finalidad de fortalecer el desarrollo del sector turístico desde la perspectiva de la planificación y preparación de los diferentes actores implicados en la gestión efectiva de los riesgos y crisis en el turismo mexicano.

Se hace necesario por tanto comprender la problemática de los riesgos y crisis con exactitud y proyectar soluciones estratégicas de cara a su manifestación en el turismo a través de la planificación y preparación de los diferentes actores implicados. Estas podrán estar basadas en la implementación de diversos esquemas de gestión, como el conocido modelo de las 4Rs (Reducción- Preparación- Respuesta- Recuperación) con el fin de promover una óptima coordinación entre el sector turístico y las organizaciones públicas y privadas de gestión dentro del ámbito del desarrollo turístico sustentable, de forma tal que se minimicen los impactos 
negativos sobre en el bienestar social, económico y ambiental.

A propósito, el enfoque de la gestión sustentable de las crisis en el turismo (Rodríguez-Toubes, 2010) debe significar la integración entre los tres ámbitos de la sustentabilidad (González, 2010); es decir, las dimensiones económico-tecnológica, político-social y territorial-ambiental, tomando en consideración las escalas espaciales correspondientes a los niveles taxonómicos local, regional y global; al tiempo que las escalas temporales según horizontes pasados, presente y futuros, con la finalidad de poder comprender y corregir los impactos heredados y actuales, así como gestionar de forma preventiva los impactos potenciales.

Es por tanto objetivo general de la investigación fundamentar el proceso de planificación y preparación para la atención sustentable e integrada de riesgos y crisis en el turismo mexicano, e implementarlos mediante la construcción participativa de un plan de gestión de crisis provocadas por la inseguridad en Ciudad Juárez de acuerdo con el modelo de las 4 "R", a fin de promover una óptima coordinación entre el sector turístico y las organizaciones públicas/privadas de gestión de riesgos y crisis, de forma tal que se minimicen los impactos sobre en el bienestar social, económico y ambiental del destino y sus organizaciones.

Como resultados de la investigación se realiza la contextualización del objeto de estudio basado en el caso de México y el Estado de Chihuahua, y se presenta un análisis de las bases institucionales para la gestión de riesgos y crisis a nivel federal. Atendiendo a tales referentes se construye de forma participativa un plan para la gestión de crisis en el turismo de Ciudad Juárez utilizando el modelo de las 4 "R", el cual está basado en el caso demostrativo de las crisis provocadas por situaciones de inseguridad; en el mismo se incluye la justificación del caso objeto de estudio, un diagnóstico situacional según percepción social de la problemática, y la proyección estratégica fundamentada en la integración participativa de los componentes esenciales de la planificación turística: objetivo estratégico; principios básicos; Factores Clave de Éxito; estructura por etapas; estrategias; líneas priorizadas de actuación; esquema de procedimientos; y manejo de riesgos e impactos.

\section{Revisión de la literatura como referente de aprendizaje Contribuciones de la teoría explicativa a la gestión de riesgos y crisis en el turismo.}

La investigación en el ámbito de los riesgos y las crisis en el turismo ha puesto de manifiesto que este es un sector propenso a recibir el impacto negativo de acontecimientos, tanto naturales como provocados por la sociedad (González, et al, 2007; Rodríguez-Toubes, 2011); por lo que los efectos de una crisis pueden ser más devastadores, y a su vez, la misma 
estructura del sistema es más propensa a la generación y propagación en cadena de las crisis (Rodríguez-Toubes, 2011). Se ha constatado que el turismo es muy vulnerable ante los desastres, ya que estos pueden tener efectos catastróficos y sostenidos a largo plazo para los destinos / organizaciones y la economía en general (Mitroff, et al., 2002; Wilks, et al., 2003; Pennington-Gray, et al., 2012). Por tanto, es necesario centrarse en la planificación y preparación para la gestión de las crisis que impactan negativamente sobre las actividades turísticas (Aktas, et al., 2005; Pennington-Gray, et al., 2011; Villegas, et al., 2012).

La Reunión de Examen de la Organización Mundial del Turismo /OMT/ sobre la integración entre el turismo y la gestión de emergencias (Mount Macedon, Australia, 22-23 de septiembre) declaró entre sus conclusiones preliminares que a pesar de que los países aspiran claramente a integrar la gestión de riesgos y crisis, en la práctica, dicha integración sigue siendo limitada (OMT, 2011). Al respecto, el Sr. Glaesser, coordinador del Programa de Gestión de Riesgos y de Crisis de la OMT, se congratuló que estuviera dándose una creciente tendencia a la integración en la formulación de políticas gubernamentales, destacando la iniciativa de la Red de Respuesta ante Emergencias Turísticas /TERN/ de enfocar la gestión de riesgos y de crisis de manera global, lo cual contribuye a la sustentabilidad y coordinación en todo el mundo, alentando a la colaboración intersectorial para detectar los principales riesgos, peligros y crisis, y buscar respuestas (Ibídem).

Las pérdidas por concepto de desastres naturales se han acrecentado a nivel mundial. En la última década se reportaron más de un millón de personas muertas y mermas económicas por 44000 millones de dólares sólo en 1991, aumentando a 60000 millones un año más tarde (WTO y WMO, 1998: 1; En Palafox, et al., 2008); asimismo la World Meteorological Organization /WMO/ reportó pérdidas económicas por 6500 millones de dólares sólo en 2003 debido a tormentas y huracanes. En este sentido, las cifras de la Secretaría de Gobernación de México reportan que en el país se han perdido más de 100 vidas y cerca de 700 millones de dólares en promedio anualmente, sólo en la última década (Ibídem).

De igual forma durante los meses de abril y mayo de 2015 dos terremotos de gran intensidad afectaron a Nepal dejando un saldo de más de 8400 personas muertas, 20000 heridos y 300000 casas fueron reducidas a escombros. En marzo de 2015 el ciclón Pam provocó una gran destrucción en Vanuatu, isla del Pacífico, afectando a la mitad de la población, cifra que incluye 82000 niños (Cutter, et al, 2015: 277).

Tomando en consideración situaciones como las anteriores se examinaron los resultados de la planificación de crisis y preparación de los Estados Unidos en el ámbito del turismo, reconociendo la forma en que han 
integrado las organizaciones de gestión de destinos y gestión de crisis en el turismo de Florida ( $\underline{E n}$ Pennington-Gray, 2011; Kim, et al., 2012). Dicha experiencia pone de manifiesto que las Organizaciones de Gestión de Destinos /OGD/ en el ámbito local están a la vanguardia en la planificación de la gestión de riesgos y crisis para el sector. Reconoce así mismo que las organizaciones turísticas deben estar preparadas para ayudar a los empleados y a los turistas que visitan sus destinos, precisando que una evaluación de la planificación de la gestión de crisis permitirá a las organizaciones y destinos turísticos estar preparados cuando se enfrentan a eventos catastróficos (Faulkner, 2001; Frisby, 2002; De Sausmarez, 2004, 2007; Pennington-Gray, et al., 2012).

También se consideraron experiencias de intervenciones en casos de emergencia como la de 2011 en Japón, las inundaciones e incendios de Australia, y lecciones de gestión de riesgos y crisis (Henderson, 2007; Rodríguez-Toubes, 2011) como la fiebre aftosa en el Reino Unido en 2001, la marea negra del petrolero Prestige en 2001 frente a las costas de Galicia, y el tsunami del sudeste asiático en 2004. Una característica recurrente que se advierte en estos casos es la dificultad para superar las percepciones negativas en cuanto a seguridad (OMT, 2011) y a situaciones de crisis, tales como las sistematizadas por Pennington-Gray (2011) respecto al derrame de petróleo en el Golfo que provocó un 6,6 \% de disminución en los gastos de viaje (aprox. \$4,000,000,000) y la recaudación de impuestos de ventas (aprox. \$240.9 millones); el terremoto de Chile que provocó la caída de 14 \% en los viajes a América del Norte en 2010; y las inundaciones en Machu Pichu que en los últimos años han provocado pérdidas de aproximadamente \$ 60 millones.

Tales situaciones están estrechamente relacionadas con la información, la comunicación y la disponibilidad recursos económicos y financieros para responder ante riesgos y eventos de crisis. En ocasiones la información ofrecida es errónea, como “cuando el tifón Haiyan se acercó a las Filipinas en 2013 y los encargados de la gestión de emergencias locales comunicaron a los residentes que un tsunami se acercaba - en lugar de emitir una advertencia de marejada” (Cutter, et al, 2015: 278). Al tiempo que en la mayoría de los casos los recursos financieros de que se dispone no cubren las necesidades de actuación previstas, como el caso en que "el costo estimado para la protección de Nueva Orleans, Luisiana, en contra de los huracanes e inundaciones fue de US \$ 14 millones de dólares antes del huracán Katrina en el 2005; en tanto el total de las pérdidas producidas en ese año fue de \$ 125 mil millones” (Ibídem).

Para México la situación no es diferente. Desde 1931 a 2008 se presentaron 60 huracanes, y se espera que estos incrementen en frecuencia e intensidad con efectos directos sobre el turismo litoral (Palafox, et al., 2013), 
por lo que las estrategias de prevención y alertas tempranas son aún de mayor importancia. Según el Centro Nacional de Prevención de Desastres /CENAPRED/ en los meses de mayo a noviembre se presentan en promedio 23 ciclones con vientos mayores a $63 \mathrm{~km} / \mathrm{h}$, de los cuales 4 inciden cada año sobre el territorio nacional o se acercan a menos de $100 \mathrm{~km}$. La evaluación del CENAPRED en el periodo 2000 - 2010 para el Estado de Quintana Roo reconoció pérdidas en el orden de los 22091 millones de pesos, mientras que en Nayarit fueron más de 1 918, en tanto se registraron 29 muertes en Quintana Roo y 80 en Nayarit (Ibídem). Los efectos de tales crisis en el turismo de México quedan tristemente demostrados a través de las recientes inundaciones de 2013 provocadas por las tormentas Manuel e Ingrid.

Otros ejemplos muestran una situación similar. La nueva influenza A1H1N1 en 2009 desplomó la actividad turística de México provocando que la suspensión de vuelos se multiplicara, principalmente los provenientes del extranjero; a la cancelación de vuelos hacia y desde México se aunó la reducción temporal del 50 \% de los 450 vuelos semanales que realizaba en aquel entonces Continental Airlines, los hoteles reportaron una ocupación entre 10 y $30 \%$, en contraste con el $80 \%$ registrado tradicionalmente (González, 2009). Durante las inundaciones en Tabasco (2007) se presentó uno de los mayores deslizamientos de tierra ocasionando el deceso de 25 personas en Juan de Grijalva, municipio de Ostuacán, Chiapas, lo que provocó un tapón que obstaculizó el cauce del río Grijalva, el cual puso en riesgo de inundación en partes del estado y en Tabasco (Centro Nacional de Prevención de Desastres, 2007).

\section{Definición de variables conceptuales utilizadas en la investigación: riesgo y crisis}

Según la Dirección General de Protección Civil y Emergencias del Ministerio del Interior de España un riesgo es la "probabilidad de que se desencadene un determinado fenómeno o suceso que, como consecuencia de su propia naturaleza o intensidad y la vulnerabilidad de los elementos expuestos puede producir efectos perjudiciales en las personas o pérdidas de bienes”. Reconoce el concepto de “vulnerabilidad como determinante del tipo y cantidad de los daños acaecidos...y la susceptibilidad a experimentar daños como consecuencia del fenómeno peligroso”, así como el concepto de "resiliencia para designar la capacidad de una sociedad, resistiendo o cambiando, con el fin de mantener un nivel aceptable en su funcionamiento tras la ocurrencia de un fenómeno o suceso peligroso" http://www.proteccioncivil.org/riesgos_[recuperado el 15 de junio de 2015].

El Centro Internacional para la investigación del Fenómeno de El Niño /CIIFEN/ aporta que el riesgo es "la combinación de la probabilidad de que se produzca un evento y sus consecuencias negativas”, identificando que 
"los factores que lo componen son la amenaza (fenómeno, sustancia, actividad humana o condición peligrosa que puede ocasionar la muerte, lesiones u otros impactos a la salud, al igual que daños a la propiedad, la pérdida de medios de sustento $\mathrm{y}$ de servicios, trastornos sociales $\mathrm{y}$ económicos, o daños ambientales) y la vulnerabilidad (características y circunstancias de una comunidad, sistema o bien que los hacen susceptibles a los efectos dañinos de una amenaza)" http://www.ciifen.org/index.php?option=com_content\&view=category\&id=8 4\&layout=blog\&Itemid=111\&lang=es_[recuperado el 15 de junio de 2015].

A la vez reconoce que "los factores que componen la vulnerabilidad son la exposición, susceptibilidad y resiliencia. Define que la "exposición es la condición de desventaja debido a la ubicación, posición o localización de un sujeto, objeto o sistema expuesto al riesgo; la susceptibilidad es el grado de fragilidad interna de un sujeto, objeto o sistema para enfrentar una amenaza y recibir un posible impacto debido a la ocurrencia de un evento adverso; y la resiliencia es la capacidad de un sistema, comunidad o sociedad expuestos a una amenaza para resistir, absorber, adaptarse y recuperarse de sus efectos de manera oportuna y eficaz, lo que incluye la preservación y la restauración de sus estructuras y funciones básicas” (Ibídem).

La crisis es comprendida como "un proceso extraordinario no deseado, a menudo inesperado y limitado en tiempo con posibilidades de desarrollo ambivalente. Exige decisiones inmediatas y contramedidas con el fin de influir positivamente en el desarrollo ulterior para la organización / destino y limitar las consecuencias negativas tanto como sea posible" (Pennington-Gray, 2011). En opinión de la referida autora las crisis pueden ser inducidas por la naturaleza: avalanchas, inundaciones, epidemia médica, terremoto, huracán, deslizamientos de rocas/lodo, incendios forestales, tornados, tormentas, tsunami; o inducidas por el hombre: lesiones / muerte de un visitante, violencia laboral, delincuencia (asalto, asesinatos, disturbios), secuestro, accidente aéreo, avería de viaje, derrame industrial/químico, autobús/vehículo accidentado, desastre en crucero/ferry, derrame de petróleo en el área natural.

\section{Enfoque metodológico para la gestión de riesgos y crisis en el turismo}

Basado en el análisis de la literatura se adopta como enfoque metodológico de la investigación el modelo presentado por Wilks y Moore (2003) para la gestión de crisis en un destino turístico, denominado modelo de las 4 Rs (Rodríguez-Toubes, 2011), el cual ha sido implementado y desarrollado por el Instituto de Gestión de Crisis en el Turismo de la Universidad de Florida (Pennington-Gray, 2011). Este modelo se fundamenta en la integración de 4 etapas, las cuales corresponden a la Reducción con el fin de impedir un desastre, reducir la posibilidad de que ocurra y atenuar sus 
efectos nocivos; Preparación mediante la planificación, comunicación, desarrollo de habilidades de gestión y test de preparación; Respuesta durante el momento de la verdad; y Recuperación posterior al evento de crisis de los niveles operativos previos, reanudación de las operaciones completas y estudio de las lecciones aprendidas (Pennington-Gray, 2011).

Este posicionamiento metodológico se enriquece con los aportes realizados por Wilks y Moore (2003) con respecto a los aspectos a considerar para la gestión de crisis en el turismo basado en el modelo de las 4 Rs.” Identifican que para la Reducción de la crisis es necesario implementar políticas, protocolos, procedimientos y acciones de observación y vigilancia; para la Preparación es requerida la elaboración de planes de gestión y medidas de salud y seguridad; para la Respuesta ante la crisis se necesita la implementación de procedimientos de actuación ante emergencias, investigación, asistencia a familias y comunicación; y para la Recuperación se procede con el interrogatorio de los damnificados, y la elaboración de planes de continuidad ante los efectos de la crisis.

De igual forma se reconocen los indicadores sobre la crisis en el turismo que pueden servir de base al estudio práctico y evaluación de dichos eventos. De acuerdo con la propuesta de Ritchie y Crouch (2003) se diferencian indicadores subjetivos del consumidor, los cuales están relacionados con los componentes de organización y gestión, así como indicadores objetivos propios del sector turístico. Esta diferenciación permite distinguir entre las actividades que las organizaciones turísticas proyectan como efectivas para la gestión de riesgos y crisis, y la precepción que tienen los afectados cuando están expuestos a las consecuencias de las mismas, lo cual es un importante criterio para la evaluación de la efectividad de los sistemas de gestión de riesgos y crisis.

Además se reconocen los cuatro principios generales que deberán sostener la gestión de crisis en el turismo, dada la naturaleza diversa, fragmentada e independiente del sector turístico, así como la fragilidad de los flujos turísticos con relación a los riesgos percibidos o crisis actuales / potenciales. Estos son (Sharpley, 2005a: 284, En Rodríguez-Toubes, 2011): Coordinación; Colaboración; Comunicación; y Compromiso (4 “Cs”).

En realidad se trata de un problema extremadamente complejo del que hay mucho por asimilar y hacer. En opinión de Cutter y colegas hay 3 lecciones aún por aprender para enfrentar la amenaza de peligros, estos son: construir bien para salvar la vida y las propiedades en regiones propensas a desastres; invertir en la mitigación antes del desastre, ya que disponer del 5$10 \%$ de los fondos necesarios para la recuperación después de un desastre salva vidas y recursos; y estar preparados mediante planes de gestión de emergencia, sistemas de alerta, educación, sensibilización y comunicación de riesgos (Cutter, et al, 2015: 278). 


\section{Metodología aplicada en la investigación}

El estudio corresponde a una investigación aplicada en la que se utiliza un enfoque deductivo (de la teoría explicativa a un caso de estudio), la cual se orienta a la solución práctica de un problema y al mejoramiento continuo de la gestión de riesgos y crisis en el turismo; corresponde a una investigación de carácter cualitativa, transversal y propositiva con enfoque multidisciplinar. Durante la misma se realizó una detallada revisión documental y normativa; entrevistas con especialistas, investigadores, académicos y gestores; análisis de estudio de casos; sistematización de datos secundarios; y trabajo grupal mediante la implementación de 3 grupos focales realizados a través de un estudio piloto, así como la aplicación de entrevistas de profundidad para cubrir vacíos de información.

La unidad de análisis para el desarrollo de la propuesta corresponde a Ciudad de Juárez, y la unidad de muestreo a la población o grupos de personas residentes en la misma, los que fueron seleccionados de forma intencionada para el estudio mediante el trabajo en grupos. Fueron utilizados métodos empíricos dirigidos a la intervención, registro, medición cualitativa, análisis, e interpretación de la realidad, tales como la observación, análisis de documentos, encuesta, criterio de especialistas, estudio de casos y grupos focales; así como métodos teóricos para la comprensión de la teoría científica producida hasta el presente, identificación de regularidades y características esenciales del fenómeno objeto de estudio, como el analíticosintético, inductivo-deductivo, histórico-lógico, sistémico-estructural y la modelación conceptual. Con relación a los métodos seleccionados fueron utilizadas técnicas conceptuales, descriptivas y proyectivas.

El estudio piloto se sustentó en la construcción de un caso basado en la tipología de riesgos y crisis provocadas por situaciones de inseguridad en Ciudad Juárez, Chihuahua. El mismo se desarrolló mediante el levantamiento de información aportada por los grupos de discusión, con los cuales se debatió el impacto percibido sobre la seguridad y el bienestar de los visitantes y residentes locales como posibles factores impulsores de crisis social con consecuencias negativas para el turismo, así como la precepción sobre el proceso de toma de decisiones relativo al mismo, cuyos resultados se comentan en el artículo.

\section{Contextualización de la problemática objeto de estudio}

\section{Panorama general en México según tipos de eventos seleccionados}

México ha experimentado etapas difíciles en muchas ocasiones durante su historia reciente, pero al enfocar el análisis en esta última década es posible distinguir diferentes factores que han desencadenado diversas crisis en diferentes regiones del país, las cuales con magnitud y alcance espacial diferenciado abarcan prácticamente todos los tipos de eventos que 
pueden impactar negativamente sobre el turismo. Entre estas se toman como muestra de estudio las que abarcan según su tipología fenómenos de crisis provocadas por violencia, desastres naturales y eventos de salud, las cuales han sido seleccionadas por su significación a nivel nacional y se caracterizan brevemente.

- $\quad$ Crisis provocadas por situaciones de inseguridad. Según reportes del Banco de México en el 2011 la crisis económica mundial y la violencia provocaron una disminución del $13 \%$ en la entrada de viajeros internacionales http://www.xepl.com.mx/ [recuperado 11 de abril de 2015]. El 2010 rompió récord ya que fue el año más violento con 12 mil 658 ejecuciones, y también el de menor número de visitantes extranjeros, incluso por debajo de 2009, cuando la emergencia sanitaria por la influenza http://mexico.cnn.com/nacional/2014/02/01/mexico-termina-enero-con2805-casos-de-influenza-y-295-muertes_[recuperado 11 de abril de 2015]. Algunos países como Estados Unidos, Francia y Australia han emitido alertas para prevenir a los turistas sobre la violencia en México, particularmente en Chihuahua, Nuevo León, Guerrero, Tamaulipas, Baja California, Coahuila, Michoacán, Durango, Sinaloa y Sonora, agravando la situación para el sector http://www.xepl.com.mx/ [recuperado 11 de abril de 2015]. Mensajes han reportado que agencias de viaje proyectaron caídas en la demanda de vacaciones con destino a Jalisco y lugares de interés del estado por los índices de criminalidad y hechos de intimidación. Estos acontecimientos han estado asociados con jornadas violentas en Jalisco que han incluido narcobloqueos y tiroteos, dejando altos saldos de muertos, heridos y detenidos, mientras la ola de inseguridad se ha extendido a otros importantes destinos como Puerto Vallarta y Guanajuato http://diario.mx/Local/2015-05-02_b3106f34/proyectan-agencias-de-viajeque-se-desplomen-destinos-a-jalisco/ [recuperado 10 de mayo de 2015].

- Crisis provocadas por fenómenos naturales. En México se han presentado ciclones devastadores, como el caso de Gilbert en 1988 (Rosengaus, Jiménez, \& Vazquez, 2014). El paso reciente del huracán “Odile” por San José del Cabo y Los Cabos San Lucas provocó que al menos 30 mil vacacionistas se quedaran varados y fueron evacuados http://diario.mx/Nacional/2014-09-19_e89aa82d/desastre-natural-en-loscabos-(fotogaleria)/ [recuperado el 15 de junio de 2015]. Este destino fue duramente golpeado por el huracán de categoría 3; los 250 mil habitantes se resguardaron en casas y albergues; los hoteles estuvieron al $43 \%$ de ocupación con cerca de 30 mil turistas refugiados. El recuento de los daños fue de 8,000 postes, 600 torres de alta tensión y fibra óptica telefónica, 52 hoteles, el Aeropuerto Internacional y 9 mil 300 casas devastadas, así como 7 muertos y $\$ 14,869$ millones de daños totales http://diario.mx/Anuario2014/2014-12-31_00686f34/devasta-huracan-odile/ 
[recuperado el 15 de junio de 2015].

- $\quad$ Crisis provocadas por eventos de salud. En febrero de 2014 CNN Mexico públicó que hasta el 1 de febrero de ese mismo año se registraron 2,994 casos de influenza en el país y 314 fallecimientos debido a la enfermedad de acuerdo con el reporte de la Secretaría de Salud (SSA). Según su página de internet, al menos 2,544 personas enfermaron de influenza AH1N1, la que causó una pandemia en México durante 2009; también menciona que de las 314 muertes ocurridas en 27 estados del país, 290 fueron por AH1N1. http://mexico.cnn.com/nacional/2014/02/01/mexicotermina-enero-con-2805-casos-de-influenza-y-295-muertes [recuperado el 15 de abril de 2015].

\section{Problemática en Chihuahua según tipos de eventos seleccionados.}

Chihuahua es el estado más extenso de México y ocupa una posición central en la frontera con Estados Unidos, lo cual lo convierte en puerta de entrada a América Latina. Presenta marcados contrastes geográficos entre las sierras y la altiplanicie, así como notables diferencias culturales y socioeconómicas, lo que determina un escenario peculiar para la gestión de riesgos y crisis. Ciudad Juárez es la más poblada del estado, ocupa una posición fronteriza neurálgica debido a la inseguridad y violencia experimentadas durante los últimos años. Esta ciudad conforma junto a El Paso, Texas, una de las urbes binacionales más grandes del mundo (Morales, et al., 2013), lo cual la convierte en un interesante campo para la investigación y la gestión de problemáticas relacionadas con el desarrollo del turismo fronterizo.

El estado es afectado por diversos acontecimientos, tales como fuertes lluvias, inundaciones, sequías, epidemias, tormentas, deslizamientos de rocas, incendios forestales, nevadas, lesiones de visitantes, actos delictivos, accidentes, entre otros. Es frecuente escuchar comunicados como "la Secretaría de Gobernación emitió declaratorias de desastre natural para un municipio de Chihuahua...afectado por las fuertes lluvias de los últimos días,...en Chihuahua se declaró como zona de desastre natural al municipio de Hidalgo del Parral, con lo cual tendrá acceso a los recursos del Fondo de Desastres Naturales /FONDEN/ para que atienda los daños ocasionados por las severas lluvias que se presentaron entre el 19 y 21 de septiembre pasado [2013], causadas por el huracán Manuel”.

...”Durante la instalación del Comité de Evaluación de Daños del FONDEN, el gobierno de Chihuahua manifestó su interés en acceder a los recursos a través de la figura de apoyos parciales inmediatos, para atender de manera oportuna los aspectos prioritarios y urgentes tendentes a la atención inmediata de la infraestructura dañada. El comité, integrado por funcionarios federales y locales responsables de los sectores afectados, evaluó los daños 
ocasionados en la infraestructura y cuantificó los recursos necesarios para su recuperación...La Coordinación de Protección Civil de la SEGOB indicó que con estas declaratorias solicitadas por los gobiernos estatales se activaron los recursos del FONDEN para que puedan atender las necesidades alimenticias, de abrigo y de salud de los afectados http://mexico.cnn.com/nacional/2013/09/27/municipios-de-chihuahua-yguanajuato-declarados-en-desastre-por-lluvias_[recuperado el 05 de junio de 2015].

En el estado se han presentado una serie de crisis que han afectado de manera directa al sector turístico, entre los que se encuentran la recesión económica de los Estados Unidos, la violencia, y salud social, por mencionar tan solo algunos de los eventos que han incidido negativamente sobre el turismo en diversos destinos. De igual forma para el territorio se resumen según su tipología fenómenos de crisis provocadas por violencia, desastres naturales y eventos de salud de significación a nivel regional, los cuales se caracterizan brevemente.

- Crisis provocadas por situaciones de inseguridad. De acuerdo con un artículo publicado por “El Siglo de Torreón”, la violencia que afectó a la mayor parte del Estado de Chihuahua en el 2010 tuvo incidencias significativas sobre diferentes sectores turísticos. Por ejemplo, la presencia en los destinos receptivos disminuyó hasta en un $15 \%$ en ese mismo año; además, las reservaciones en hoteles se desplomaron en un 20\%. A su vez, el turismo internacional, principalmente el estadounidense decreció en un 40\%. El presidente de la Asociación de Maquiladoras y Exportadoras reportó que durante el primer trimestre de 2009 el sector tuvo una recaída significativa en cuanto al turismo industrial http://www.elsiglodetorreon.com.mx/noticia/509520.baja-15x-afluenciaturistica-en-chihuahua.html [recuperado 10 de mayo de 2015]. En regiones como Guachochi el turismo se vio disminuido hasta en un 80 \% debido a los problemas de inseguridad surgidos a partir del 2008 http://diario.mx/Estado/2013-02-04_cb9e3422/derrumbo-violencia-turismoen-la-sierra/ [recuperado el 21 de marzo de 2015]. De acuerdo con un conteo realizado por la asociación civil con datos del Sistema Nacional de Seguridad Pública /SNSP/ y el Instituto Nacional de Estadística, Geografía e Informática /INEGI/, en Ciudad Juárez se registraron 485 homicidios durante 2013, lo cual resultó en una tasa de 37 homicidios por cada 100 mil habitantes (Figueroa, 2014). El pueblo mágico de Creel ha comenzado a recuperar el turismo nacional y específicamente el procedente de Ciudad Juárez. Desde la masacre que se registró en ese destino -en la que mataron a 11 personas en el 2008- el turismo se vino abajo, principalmente el internacional, que aún no recuperan. Fueron cerradas empresas que se dedicaban a ofrecer tours, se despidieron empleados de los hoteles y de otros 
negocios debido a la situación de inseguridad http://diario.mx/Economia/2013-10-04_3f201804/tras-violencia-juarensesregresan-a-creel/ [recuperado el 21 de marzo de 2015]. Esta problemática que caracterizó a Chihuahua fue conocida internacionalmente, por lo que el Gobierno de Canadá emitió una alerta en su país de no viajar al estado a menos que fuera estrictamente necesario debido a los altos niveles de inseguridad, en un desglose que hace de los estados de México donde hay riesgo para los turistas http://diario.mx/Estado/2013-12-14_e66fe41a/alertacanada-no-viajar-a-chihuahua/_[recuperado el 21 de marzo de 2015].

- Crisis provocadas por fenómenos naturales. En diciembre del 2013 diez municipios del estado estuvieron bajo nieve y fueron cerrados cinco tramos carreteros según información que ofreció la Unidad Estatal de Protección Civil. Los municipios en que se registró nieve y aguanieve refirieron acumulados de hasta 6 centímetros, destacando Janos, Casas Grandes, Madera, Ignacio Zaragoza, Gómez Farías, Temósachi, Guerrero, Uruachi, Bocoyna y Ocampo http://diario.mx/Estado/2013-1220_2760cfbd/cae-nieve-en-10-municipios-cierran-tramos-carreteros\#

[recuperado el 21 de marzo de 2015]. En el 2013 la Secretaría de Gobernación declaró 21 municipios del estado en emergencia, entre ellos Ciudad Juárez, debido a la ocurrencia de una nevada severa en diciembre de 2012 y enero de 2013 (Gallegos, 2013). En febrero de 2011 se produjo una de las más grandes nevadas debido a un fuerte frente frío que azotó a Ciudad Juárez, provocando un descenso en las temperaturas de hasta $18^{0}$ bajo cero, lo que causó interrupción en las operaciones del aeropuerto internacional, la central camionera y los cruces internacionales de la ciudad; fue necesario el cierre de carreteras ante la alerta roja por pavimento cristalizado y fuertes ráfagas de viento con hasta $30 \quad \mathrm{~km} / \mathrm{hora}$ http://www.informador.com.mx/mexico/2011/268226/6/se-registrantemperaturas-de-18-grados-bajo-cero-en-ciudad-juarez.htm [recuperado el 05 de junio de 2015]. No solo nevadas han afectado el territorio, sino también lluvias torrenciales que han provocado desastres en diferentes ciudades, así como prolongadas sequías. En el año 2013, la SEGOB emitió una Declaratoria de Emergencia para Ciudad Juárez y Chihuahua como consecuencia de las inundaciones provocadas por las lluvias que se presentaron en el mes de septiembre, las que también ocasionaron desbordamientos de ríos en ambas ciudades (Vallejo, 2013).

- $\quad$ Crisis provocadas por eventos de salud. En Chihuahua se presentó una crisis de salud cuando empezaron a registrarse los primeros casos de AH1N1. En el 2011 las autoridades del estado reportaron 15 casos de influenza en el territorio. Además, 8 de los casos asociados con esta enfermedad y que motivaron una alerta sanitaria nacional en 2009 se registraron en Ciudad Juárez, 6 en la Ciudad de Chihuahua y 1 en 
Cuauhtémoc http://mexico.cnn.com/nacional/2011/03/25/chihuahua-registra15-casos-de-influenza-ah1n1-confirma-el-gobernador [recuperado el 15 de junio de 2015].

\section{Bases institucionales para la gestión de riesgos y crisis en el turismo mexicano.}

Para comprender la problemática con exactitud y proyectar soluciones estratégicas frente a la manifestación de riesgos y crisis en el turismo se realizó la sistematización de la información correspondiente a algunos de los más importantes órganos de gestión a nivel nacional, los cuales tienen diferentes entidades para la coordinación entre los tres niveles y órdenes de gobierno. En los mismos se incorporan elementos de sus misiones, objetivos o alcances de gestión de acuerdo con su responsabilidad social. En base a esta se identificaron las siguientes regularidades programáticas derivadas del análisis combinado de todos los documentos revisados, las que pudieran servir de soporte a la gestión integrada de riesgos y eventos de crisis (Figura 1):

Figura 1 Nube de palabras sobre el proceso de gestión de crisis en la documentación revisada.

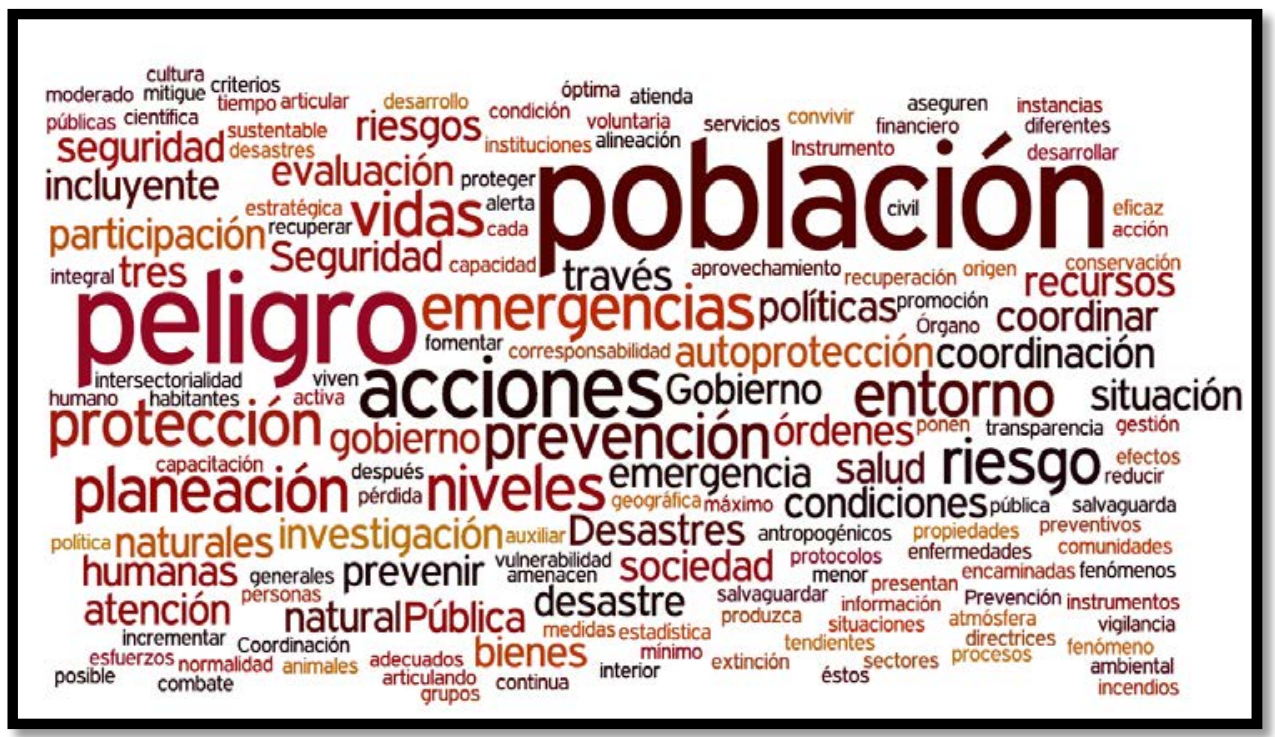

Fuente: Elaboración propia.

- $\quad$ Políticas públicas, directrices, sistemas de planificación, evaluación y transparencia.

- Coordinación y articulación entre los tres niveles y órdenes de Gobierno.

- $\quad$ Coordinación y participación del gobierno y de todos los sectores de la sociedad (intersectorialidad). 
- $\quad$ Conciencia y comprometimiento ciudadano, ética y responsabilidad social ante eventos de crisis.

- $\quad$ Protocolos de actuación antes, durante y después de la situación de emergencia.

- $\quad$ Atención a fenómenos y desastres de origen natural y/o humano.

- $\quad$ Auxilio y salvaguarda de vidas humanas, sus bienes y su entorno, así como de los animales.

- $\quad$ Sistemas integrados de gestión de emergencias y atención eficaz de desastres.

- $\quad$ Condiciones de seguridad pública.

- $\quad$ Prevención, alerta, atención y mitigación de riesgos.

- $\quad$ Autoprotección y adaptación para convivir con los riesgos, y desarrollo de capacidad de las personas y las comunidades a través de la acción voluntaria ante casos de emergencia y en situaciones de desastre.

- Identificación de grupos de la población que viven en condición de vulnerabilidad.

- $\quad$ Familiarización con los niveles de alerta según peligro potencial.

- Indicación en cada situación sobre qué acciones desarrollar y cómo acometerlas.

- Fortalecimiento de instrumentos financieros de atención y recuperación de los efectos de eventos de crisis.

- Investigación, monitoreo, vigilancia, y difusión.

- $\quad$ Generación de información estadística y geográfica.

- Coordinación de esfuerzos para recuperar las condiciones de normalidad en el menor tiempo posible.

- $\quad$ Fortalecimiento de servicios de emergencias.

En la nube de palabras (Figura 1) es posible identificar tres grupos de términos que se relacionan con una variable determinada del proceso de gestión de las crisis. Estas son:

- $\quad$ Receptor del evento de crisis: población, vidas, entorno, recursos, bienes, gobierno.

- $\quad$ Situación relacionada con la crisis: peligro, emergencia, riesgo, desastre, salud, seguridad.

- $\quad$ Respuesta ante la crisis: acción, protección, prevención, planeación, evaluación, políticas, participación, coordinación, auto preparación, atención, gestión. 
Plan para la gestión de crisis en el turismo de Ciudad Juárez basado en el modelo de las 4 “R”. El caso de las crisis provocadas por situaciones de inseguridad

\section{Justificación del caso de estudio}

Según el Instituto de Economía y Paz “El Índice de Paz Global /IPG/ del 2015 indica que el mundo se está dividiendo entre países que están disfrutando de paz y prosperidad sin precedentes, y países sucumbiendo más y más en violencia y conflicto” http://www.visionofhumanity.org/\#/page/ourgpi-findings [recuperado el 17 de junio de 2015]. Agrega que "con la creciente amenaza del terrorismo, la escalada de varios conflictos internos, y otros brotes de disturbios en el mundo, nunca ha habido un momento más pertinente para cuestionar el estado de paz, y para entender lo que tenemos que hacer para mitigar la violencia en el futuro" http://www.visionofhumanity.org/\#/page/news/1164_[recuperado el 10 de mayo de 2015]. De acuerdo con la citada fuente la calificación de México en el IPG es de 2.53, por lo que ocupa el lugar 144 en un total de 162 países, y el costo estimado de la violencia ha sido de US\$ 221,435,321,551. Así mismo, México se ubica en la última posición dentro de la región de Centro América y El Caribe, con un cambio de puntuación de -0.016 (IEP, 2015). El Estado de Chihuahua tiene una calificación en el IPM de 2.96 y ocupa el lugar 26 en un total de 32 estados http://www.visionofhumanity.org/\#page/indexes/mexico-peaceindex/2014/CHH/OVER [recuperado el 17 de junio de 2015].

En este contexto Ciudad Juárez vive las secuelas negativas de una marcada crisis sufrida entre los años 2008 y 2011 a consecuencia de diversos eventos de inseguridad, etapa en la que según el ranking de ciudades más violentas del mundo ocupó el segundo lugar en 2008 y 2011, el primer lugar en 2009 y 2010, el lugar 19 en 2012, el lugar 21 en 2013 http://www.seguridadjusticiaypaz.org.mx/sala-de-prensa/759-san-pedro-sulaotra-vez-la-ciudad-mas-violenta-del-mundo-acapulco-la-segunda

[recuperado el 20 de junio de 2015], y el lugar 27 en 2014 http://arias.or.cr/informe-50-ciudades-mas-violentas-del-mundo-en-2014/

[recuperado el 20 de junio de 2015]. Esto demuestra su ubicación durante un prolongado período de tiempo entre las ciudades con más problemas de inseguridad, especialmente durante la última década.

\section{Diagnóstico situacional}

El diagnóstico situacional se basó en los resultados del estudio realizado mediante los grupos focales y entrevistas en profundidad, los cuales permitieron sistematizar la siguiente información según tipos y niveles de percepción de los participantes: 
Percepción por parte de los visitantes con respecto a la seguridad y el bienestar como factores desencadenantes de riesgos y crisis en el turismo 1. Apreciación de la ciudad como un destino inseguro.

2. Temor en los residentes fronterizos procedentes de EEUU de ser abordados o robados al cruzar a la ciudad.

3. Pocos centros y puntos de información al visitante, reforzado por el insuficiente rol de informante que corresponde a los diferentes actores de la ciudad.

4. No existencia de una guía turística confiable que permita al visitante desenvolverse en la ciudad, guiarse, informarse, viajar y sentirse cómodo.

5. Insuficiente señalética turística en la ciudad (y no turística).

6. Deficiente estado de la infraestructura en la ciudad, lo que trasmite inseguridad.

7. Problemas de vialidad y mal estado de las vías de comunicación.

8. Carencia de espacios para estacionamiento seguro en determinados lugares y tiempos de la ciudad.

9. Altas tasas de incidencias y reportes por robos en zonas determinadas de la ciudad.

Percepción por parte de los residentes locales con respecto a la seguridad y el bienestar como factores desencadenantes de riesgos y crisis en el turismo.

1. Miedo e inseguridad que ha impactado negativamente sobre el tejido social de la ciudad.

2. Inadecuado trato por parte de los oficiales de tránsito y de los federales.

3. Abuso y explotación al visitante por parte de autoridades y empresarios locales.

4. Desconfianza e inseguridad por parte de los empresarios.

5. Falta de confianza y credibilidad en tránsito y la policía por extorsión a vendedores y visitantes, multas indebidas, etc.

6. Inexistencia de una policía turística para la ciudad y de supervisores.

7. Inexistencia de un sistema coherente de actuación para prevenir y responder a los peligros de la delincuencia, a la seguridad ciudadana y de sus visitantes.

8. Falta de participación ciudadana.

Percepción del proceso de toma de decisiones con respecto a la seguridad y el bienestar como factores desencadenantes de riesgos y crisis en el turismo

1. Falta de sistematicidad en las actividades de planificación, coordinación y control. 
2. Insuficiente compromiso empresarial.

3. Falta de unidad y proyección estratégica.

4. Insuficiente rigor técnico.

5. Carencia de instrumentos en la legislación y normalización.

6. Insuficiente presupuesto y recursos federales para programas específicos de gestión en casos de riesgos y crisis para el turismo.

7. Inadecuada correspondencia entre una política turística coherente y el presupuesto requerido para la implementación de la gestión integrada de riesgos y crisis.

8. Falta de proyección estratégica y de planificación turística integrada a nivel de destino.

9. Insuficiente coordinación entre el sector público y privado.

10. Limitadas relaciones inter institucionales.

Derivado del análisis situacional se formula el siguiente problema estratégico para el destino: la integración entre el turismo y la gestión de riesgos y crisis provocadas por situaciones de inseguridad en la práctica es marcadamente limitada e ineficiente, debido a los altos niveles de impactos adversos que siguen reportándose, a pesar de la oportunidad existente para proyectar soluciones estratégicas participativas frente a la manifestación de riesgos y crisis en el turismo mediante la planificación y preparación de los diferentes actores implicados.

\section{Proyección estratégica}

La proyección estratégica para el proceso de gestión de riesgos y crisis provocadas por eventos de inseguridad en el destino turístico se basó en la propuesta de integración participativa de los componentes siguientes: objetivo estratégico; principios básicos; Factores Clave de Éxito; estructura por etapas; estrategias; líneas priorizadas de actuación; esquema de procedimientos; y manejo de riesgos e impactos. Los mismos se detallan de forma sintética a continuación.

\section{Objetivo estratégico general para la Gestión de Riesgos y Crisis en el Turismo provocadas por situaciones de inseguridad}

- $\quad$ Fundamentar con enfoque integrador las bases que sustentan la aplicación de la gestión de riesgos y crisis en el turismo valorando su contribución al manejo de los impactos provocados por eventos de inseguridad a nivel del destino y sus organizaciones con el fin de reducir afectaciones y/o pérdidas humanas, materiales y financieras en el mediano y largo plazo. 


\section{Principios básicos para la Gestión de Riesgos y Crisis en el Turismo provocadas por situaciones de inseguridad.}

1. Legales e institucionales:

- Disposiciones jurídicas y estructuras institucionales encargadas de desarrollar el proceso de gestión de riesgos y crisis.

- $\quad$ Formulación de políticas y directrices gubernamentales.

- $\quad$ Integración entre instituciones de gestión de riesgos y crisis en los tres ámbitos de gobierno.

2. Científico técnico y metodológicos:

- $\quad$ Basamento conceptual integrado en un sistema teórico preestablecido para comprender la problemática de los riesgos y crisis en el turismo con la mayor exactitud posible.

- Identificación de indicadores sobre riesgos y crisis en el turismo que pueden servir de base al estudio práctico y evaluación de los mismos.

- Basamento metodológico preestablecido con especificaciones de contenidos, métodos, procedimientos, etc., para su aplicación práctica.

3. Operativos:

- $\quad$ Fortalecimiento de la integración entre las organizaciones de gestión de destinos y gestión de riesgos y crisis en el turismo mediante las Organizaciones de Gestión de Destinos (OGD) en el ámbito local como vía para la planificación estratégica, táctica y operativa.

- Identificación de los actores implicados, sus roles y responsabilidades, resultando de gran importancia práctica la identificación de los grupos sociales presuntamente afectados.

- Mecanismos de participación social e institucional para cumplimentar el principio de la transparencia.

- Divulgación de información para facilitar el acceso a todas las partes.

- Tiempo y recursos materiales para la implementación y aseguramiento de la eficacia y efectividad de la gestión de riesgos y crisis en el turismo.

- Voluntad política y mecanismos prácticos para la gestión de riesgos y crisis atendiendo a decisiones multicriterio.

- Fortalecimiento de los Comités de Evaluación de Daños y de los procedimientos para la cuantificación de los recursos necesarios para su recuperación.

4. Humanos:

- Competencia y capacitación de los actores implicados en el proceso de gestión de riesgos y crisis en el turismo, desarrollando la capacitación técnica y ética de todos los implicados.

- Cultura y disposición para la participación durante todas las etapas del proceso de gestión de riesgos y crisis en el turismo.

- Formación y capacitación de los responsables del proceso de toma de 
decisiones.

Factores Clave de Éxito para la Gestión de Riesgos y Crisis en el Turismo provocadas por situaciones de inseguridad.

- $\quad$ Educación, capacitación, adiestramiento y entrenamiento. Preparación de los diferentes actores que pudieran estar implicados en eventos de riesgos y crisis bajo el supuesto de la posibilidad real de ocurrencia y la obligada necesidad de comprender integralmente el fenómeno, desarrollar habilidades y generar actitudes y comportamientos compatibles con el desempeño individual y colectivo deseado. Fortalecimiento de centros de investigación y formación para el desarrollo de capacidades en respuesta a la gestión de riesgos y crisis en el turismo.

- Organización social e institucional. Agrupación entre todos los actores que intervienen en la preparación para la gestión de riesgos y crisis en el turismo a partir de esfuerzos compartidos, ideas de valor social e institucional, basados en el objetivo común de reducir efectos negativos, promoviendo solidaridad y ayuda en casos de situaciones requeridas.

- Coordinación y colaboración. Coordinación óptima entre el sector turístico y las organizaciones públicas/privadas de gestión de riesgos y crisis dentro del ámbito del desarrollo turístico sustentable. Implicación colaborativa de todas las empresas turísticas del destino, instancias de gobierno, instituciones de gestión y la comunidad en general, así como la elaboración de los perfiles básicos de visitantes que pudieran estar implicados en la coordinación y colaboración requerida para el éxito de la gestión. Promoción de la colaboración intersectorial para detectar los principales riesgos y crisis, y buscar posibles respuestas.

- $\quad$ Provisión de recursos humanos, materiales y financieros. Desarrollo de recursos humanos especializados en la gestión de eventos de riesgos y crisis provocados por la inseguridad. Identificación, gestión y acceso a los recursos materiales y financieros para la atención a los daños y perjuicios ocasionados.

- Participación y compromiso. Participación a través de acciones e iniciativas que promuevan la actuación responsable e integración de todos los factores para el ejercicio de los protocolos establecidos, mejorando la actuación eficaz y potenciando el papel de cada participante para favorecer la mejor toma de decisiones. Compromiso basado en la convicción de generar habilidades y capacidades de actuación que contribuyan a minimizar el impacto de los eventos de crisis, con énfasis en el compromiso, sobre todo en niveles de preparación y acción preventiva.

- Integración e inclusión. Acceso de todas las personas con discapacidad y otros requisitos específicos a los mecanismos y protocolos de 
gestión de riesgos y crisis provocadas por la inseguridad.

- Información y comunicación. Elaboración y divulgación de información suficiente sobre cómo actuar ante eventos de crisis en el destino. Comunicación a los residentes locales, empresas turísticas y visitantes sobre los elementos clave contenidos en los planes de respuesta para los riesgos y crisis. Recomendaciones para promover un viaje confiable a los turistas potenciales, evitando la falsa veracidad del marketing y la publicidad engañosa.

- Asistencia y confianza. Atención personalizada, dosificada y orientada para evitar el caos, confusión miedo y falta de confianza por parte del visitante y del residente local ante la exposición a un evento de crisis con el fin de reducir las respuestas negativas ante la ocurrencia de los mismos.

- $\quad$ Evaluación, control y retroalimentación para la mejora continua del proceso de gestión de riesgos y crisis en el turismo. Evaluación sistemática del proceso de gestión, lo que permitirá a las organizaciones y destinos turísticos estar preparados cuando se enfrenten a eventos catastróficos, a la vez que servirá como mecanismo de retroalimentación para el perfeccionamiento continuo del proceso. Documentación con evidencias de cada evento durante las diferentes fases de su ciclo de vida.

\section{Estructura por etapas del Proceso de Gestión de Riesgos y Crisis en el Turismo provocadas por situaciones de inseguridad utilizando el modelo de las $4 \mathbf{R}$}

Atendiendo a los antecedentes teóricos elaborados para este estudio la estructura del proceso se integra en las siguientes etapas:

1. Reducción (antes de la crisis) enfoque preventivo / proactivo.

2. Preparación (antes de la crisis) enfoque preventivo / proactivo. Elaboración del Plan de Gestión de Riesgos y Crisis en el Turismo.

3. Respuesta (durante de la crisis) enfoque correctivo / reactivo. Implementación del plan y toma de decisiones rápidas.

4. Recuperación (después de la crisis) enfoque correctivo / reactivo.

\section{Estrategias para la Gestión de Riesgos y Crisis en el Turismo provocadas por situaciones de inseguridad}

A continuación se presentan las principales estrategias a considerar en cada una de las etapas del proceso de gestión de riesgos y crisis en el turismo.

\section{Estrategias para la Reducción}

- Inventario y caracterización de los tipos de eventos de riesgos y crisis que pueden afectar al destino/organizaciones e implementación de acciones que puedan reducir sus efectos nocivos. 
- Inventario de zonas geográficas, grupos de población y organizaciones con mayores niveles de vulnerabilidad y necesidades de atención.

- $\quad$ Estudio sobre la percepción de riesgos por parte del visitante con respecto al destino.

- $\quad$ Estudio de las capacidades institucionales para la gestión de riesgos y crisis en el turismo.

- $\quad$ Sistematización de las experiencias previas en la gestión de riesgos y crisis a nivel de destino de acuerdo con eventos anteriormente acontecidos con el fin de aprender e impedir/minimizar un nuevo desastre.

- $\quad$ Simulación, monitoreo y vigilancia de eventos de riesgos y crisis potenciales.

- $\quad$ Implementación de medidas de seguridad, salubridad, mejoramiento de infraestructuras, etc., para reducir la exposición a posibles riesgos derivados de eventos de crisis en el turismo y minimizar la posibilidad de que ocurran.

\section{Estrategias para la Preparación.}

- Identificación de los planes existentes para la gestión de tipos específicos de riesgos y crisis provocadas por la inseguridad.

- $\quad$ Elaboración participativa del plan para la gestión de riesgos y crisis en el turismo. Planes estratégicos, tácticos y operativos. Validación y pilotaje del plan mediante pruebas o test de funcionamiento en condiciones simuladas. Evaluación de la eficiencia del plan para su implementación en casos reales. Movilización y simulacros de posibles situaciones reales. Ajustes necesarios al plan y mejora continua.

- $\quad$ Elaboración de protocolos, acuerdos y procedimientos de operaciones (manuales de procedimientos por áreas de gestión: hotelería, restaurantería, espacios urbanos, atractivos, vida silvestre, etc.).

- Creación/incremento de un fondo de apoyo a empresarios y comunidades para enfrentar las crisis en el turismo.

- Relación con organizaciones y organismos nacionales e internacionales que apoyan destinos afectados por eventos de crisis.

- Inventario detallado y publicación de la información correspondiente a instituciones y organizaciones encargadas de la gestión de riesgos y crisis en el turismo.

- $\quad$ Estudio de la capacidad del destino/organización frente al impacto de eventos de crisis potenciales.

- Fortalecimiento de la capacidad de respuesta del destinos/organizaciones turísticas frente a eventos de crisis.

- $\quad$ Realización de operativos para la atención al turista y a los negocios 
turísticos en situaciones de riesgos.

- $\quad$ Constitución y operación de un Sistema Municipal de Alertas ante riesgos y crisis para el turismo.

- Implementación de programas de fomento a la cultura de la Prevención y la Protección Civil.

- Implementación de programas de desarrollo de la cultura de autoprotección para convivir y reducir los riesgos.

- $\quad$ Coordinación interinstitucional entre los diversos sistemas de gestión de riesgos y eventos de crisis existentes en la ciudad.

\section{Estrategias para la Respuesta.}

- Movilización y respuesta rápida ante la ocurrencia del evento de crisis.

- $\quad$ Actuación en tiempo de crisis según protocolos establecidos para enfrentar la crisis y proteger los intereses de visitantes, empresas y residentes locales.

- $\quad$ Manejo de los visitantes que se encuentran en el destino al momento de producirse el evento de crisis (traslados y evacuación hacia sitios seguros).

- Asistencia a visitantes y residentes en tiempo de crisis (agua, alimentos, etc.).

- $\quad$ Aplicación de procedimientos de respuesta ante emergencias (rescate, salvamento, etc.).

- Implementación de acciones de respuesta rápida para evitar la propagación en cadena de las crisis.

- $\quad$ Mantenimiento del orden, auxilio a las personas y a sus bienes.

- Control policial y ciudadano de actos delictivos como la actuación de saqueadores que aprovechan los eventos de crisis para cometer múltiples fechorías.

\section{Estrategias para la Recuperación.}

- $\quad$ Estudio de experiencias entre los diferentes damnificados basado en las interrogantes ¿Cómo lo he vivido? y ¿Cómo ha influido sobre mis experiencias?

- Balance de resultados de los daños ocasionados por el evento de crisis.

$-\mathrm{A}$
prioridad.

- $\quad$ Reanudación progresiva de las actividades sociales y productivas a nivel del destino/organizaciones. Cálculo de los tiempos de recuperación y momento en que se alcanza la estabilidad comparable a la situación de pre 
crisis.

- $\quad$ Estudio proyectivo del impacto ocasionado por el evento de crisis y retroalimentación entre las diferentes etapas del modelo de gestión de riesgos y crisis en el turismo. Reajustes necesarios.

- $\quad$ Seguimiento de impactos residuales y no previstos, así como efectos en cadena. Compensación por daños y pérdidas.

\section{Líneas priorizadas de actuación para la Gestión de Riesgos y Crisis en el turismo provocadas por situaciones de inseguridad.}

Las líneas de actuación deberán ser diferenciadas según receptores potenciales de los impactos generados por los riesgos y eventos de crisis. Estos fueron agrupados en 5 categorías las que corresponden a los atractivos turísticos e infraestructura del destino, los visitantes según perfiles de demanda real y potencial, la población local anfitriona que reside en zonas de interés turístico, las empresas turísticas y sus empleados, y la entidad de gobierno encargada de la gestión turística a nivel local (Tabla 1).

Tabla 1 Receptores de impactos ante Riesgos y Crisis en el turismo provocadas por

situaciones de inseguridad.

\begin{tabular}{|c|c|c|c|c|}
\hline $\begin{array}{l}\text { Atractivos turísticos } \\
\text { e infraestructura. }\end{array}$ & Visitantes. & Población anfitriona. & $\begin{array}{l}\text { Empresas turísticas } \\
\text { /empleados. }\end{array}$ & Oficina de Turismo. \\
\hline $\begin{array}{l}\text { Inventario de } \\
\text { atractivos en } \\
\text { correspondencia con el } \\
\text { riesgo de afectación } \\
\text { ante eventos de crisis } \\
\text { en el destino. } \\
\text { Protocolo de actuación } \\
\text { para la protección de } \\
\text { los atractivos en caso } \\
\text { de eventos de crisis. }\end{array}$ & $\begin{array}{l}\text { Familiarización con } \\
\text { la información y los } \\
\text { protocolos para la } \\
\text { actuación ante } \\
\text { eventos de crisis } \\
\text { que se presentan } \\
\text { durante su visita al } \\
\text { destino. } \\
\text { Mecanismos de } \\
\text { respuesta rápida y } \\
\text { acción oportuna } \\
\text { ante emergencias y } \\
\text { desastres. } \\
\text { Acceso fácil al } \\
\text { sistema de alertas } \\
\text { en situaciones de } \\
\text { inminente peligro. } \\
\text { Estimulación de la } \\
\text { participación a } \\
\text { favor de la gestión } \\
\text { de riesgos y crisis } \\
\text { en el turismo a } \\
\text { través de códigos } \\
\text { de comportamiento } \\
\text { responsable. }\end{array}$ & 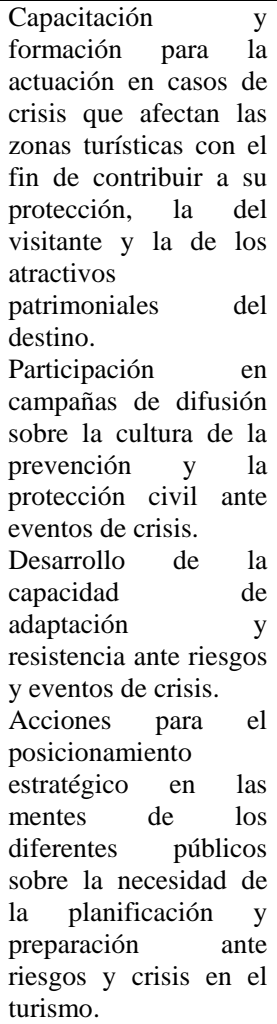 & 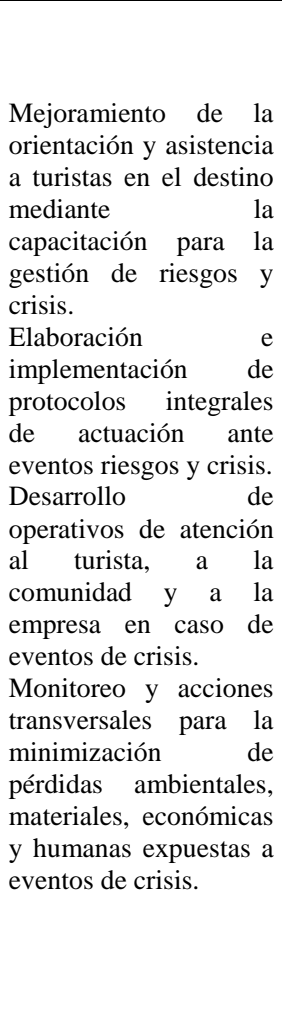 & 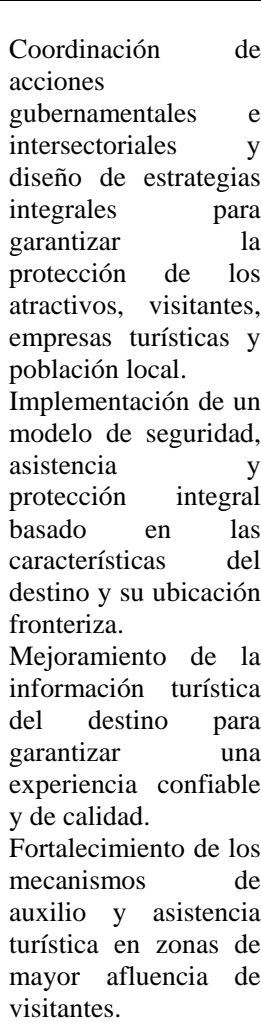 \\
\hline
\end{tabular}


En correspondencia con tales receptores se elaboraron las líneas priorizadas de actuación. A modo de ejemplo en la tabla 1 se sintetizan algunas acciones a desarrollar con el interés de propiciar la planificación y preparación para la actuación ante eventos de riesgos y crisis generados por la inseguridad en Ciudad Juárez, enfatizando en las zonas de mayor uso turístico. Estas líneas priorizadas de actuación se relacionan horizontalmente e implican a todos los actores comprometidos con la gestión, al tiempo que algunas son comunes para varios de los receptores.

\section{Esquema de procedimientos para el proceso de Gestión de Riesgos y Crisis en el turismo provocadas por situaciones de inseguridad utilizando generadores lógicos}

El procedimiento del proceso de gestión de riesgos y crisis en el turismo ante eventos de inseguridad se sustenta en un modelo conceptual elaborado para el caso del turismo según las etapas correspondientes a las 4 Rs (Figura 2). La estructuración del mismo se sustenta en las relaciones que se establecen entre el riesgo de daño o perjuicio y la probabilidad de ocurrencia, considerando los niveles de vulnerabilidad (Etapas de Reducción y Preparación), la manifestación del evento de crisis según peligros que representa dada su intensidad y frecuencia, la situación o estado de crisis que se genera, la exposición de los diferentes receptores ante el evento de crisis, así como los impactos que se derivan para la seguridad del sistema de turismo (Etapa de Respuesta), y la resiliencia que permite resistir los efectos, absorberlos, adaptarse y recuperarse de los mismos (Etapas de Respuesta y Recuperación).

Figura 2 Proceso de Gestión de Riesgos y Crisis en el Turismo basado en el modelo de las $4 \mathrm{~s}$.

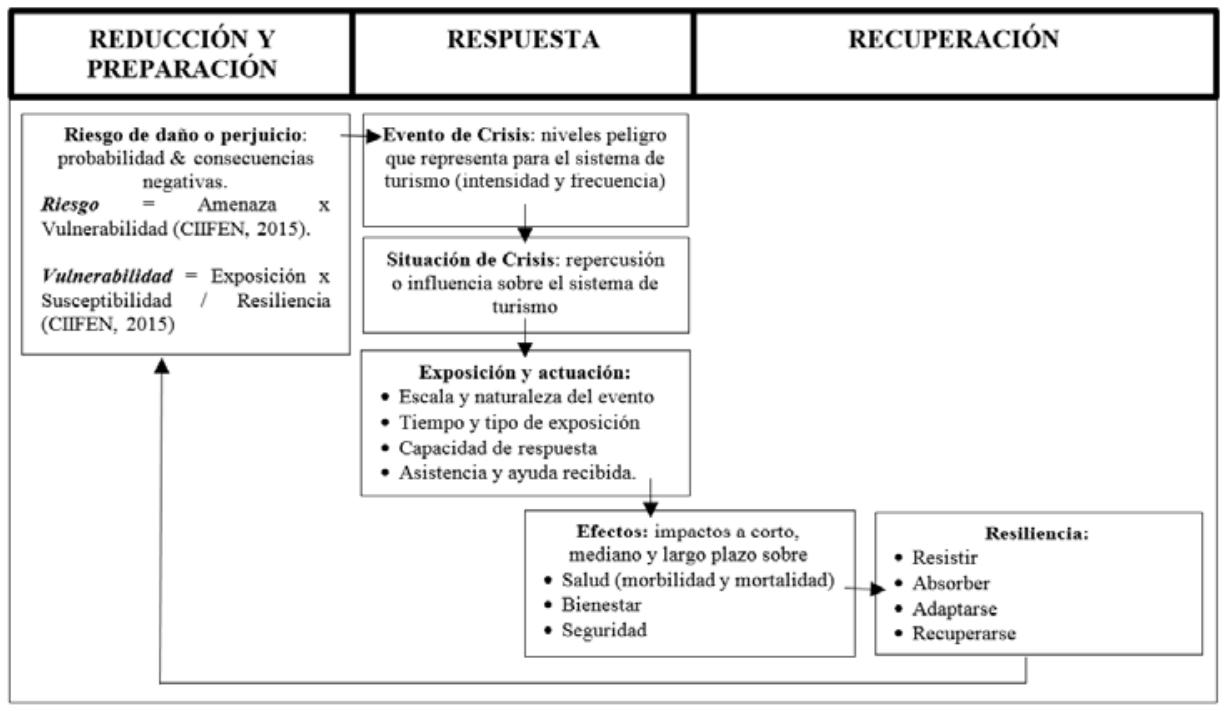

Fuente: Elaboración propia. 
Con el propósito de operacionalizar el procedimiento se elabora una matriz para la programación de las acciones priorizadas por Áreas de Resultados Clave (ARC) según las 4 etapas de gestión de riesgos y crisis (Modelo de las 4 Rs) tomando en consideración los generadores lógicos seleccionados (Tabla 2). A modo de ejemplo se selecciona en la sección de la matriz presentada el receptor de impactos correspondiente a las empresas turísticas, indicando para cada "R" un ARC y las posibles actuaciones según respuesta sintetizada en cada generador lógico.

Tabla 2 Matriz para la programación del procedimiento de Gestión de Riesgos y Crisis en el turismo.

\begin{tabular}{|c|c|c|c|c|c|c|c|}
\hline \multicolumn{2}{|c|}{$\begin{array}{l}\text { Programación de acciones } \\
\text { priorizadas por ARC para } \\
\text { cada etapa de gestión (Rs) }\end{array}$} & ¿Qué? & ¿Cómo? & ¿Quién? & ¿Cuándo? & ¿Dónde? & ¿Con qué? \\
\hline Reducción & $\begin{array}{l}\text { Información y } \\
\text { comunicación }\end{array}$ & $\begin{array}{c}\text { Promoción } \\
\text { de la } \\
\text { seguridad } \\
\text { del destino } \\
\end{array}$ & $\begin{array}{c}\text { Exposición } \\
\text { informal }\end{array}$ & $\begin{array}{l}\text { Directivos } \\
\mathrm{y} \\
\text { empleados }\end{array}$ & $\begin{array}{l}\text { Antes del } \\
\text { evento de } \\
\text { crisis. }\end{array}$ & $\begin{array}{l}\text { Áreas } \\
\text { comunes } \\
\text { de la } \\
\text { empresa } \\
\end{array}$ & $\begin{array}{l}\text { Carteles y } \\
\text { videos } \\
\text { informa- } \\
\text { tivos } \\
\end{array}$ \\
\hline Preparación & $\begin{array}{c}\text { Educación, } \\
\text { capacitación, } \\
\text { adiestramiento } \\
\text { y } \\
\text { entrenamiento }\end{array}$ & $\begin{array}{c}\text { Prepara- } \\
\text { ción para } \\
\text { la } \\
\text { actuación } \\
\text { ante } \\
\text { eventos de } \\
\text { violencia e } \\
\text { inseguri- } \\
\text { dad } \\
\end{array}$ & Talleres & $\begin{array}{l}\text { Directivos, } \\
\text { empleados } \\
\text { y } \\
\text { proveedor }\end{array}$ & $\begin{array}{l}\text { Antes del } \\
\text { evento de } \\
\text { crisis }\end{array}$ & $\begin{array}{c}\text { Salón de } \\
\text { eventos } \\
\text { de la } \\
\text { empresa }\end{array}$ & $\begin{array}{c}\text { Manual de } \\
\text { capacitación }\end{array}$ \\
\hline Respuesta & $\begin{array}{l}\text { Asistencia y } \\
\text { confianza. }\end{array}$ & $\begin{array}{l}\text { Respuesta } \\
\text { de la } \\
\text { empresas } \\
\text { ante } \\
\text { eventos de } \\
\text { crisis } \\
\text { provoca- } \\
\text { dos por } \\
\text { inseguri- } \\
\text { dad } \\
\end{array}$ & $\begin{array}{l}\text { Actuación } \\
\text { de las } \\
\text { brigadas } \\
\text { de } \\
\text { respuesta } \\
\text { rápida }\end{array}$ & $\begin{array}{c}\text { Directivos, } \\
\text { empleados, } \\
\text { comunidad, } \\
\text { visitantes }\end{array}$ & $\begin{array}{l}\text { Durante el } \\
\text { evento de } \\
\text { crisis }\end{array}$ & $\begin{array}{l}\text { Empresa } \\
\text { y su } \\
\text { entorno } \\
\text { de } \\
\text { responsa- } \\
\text { bilidad }\end{array}$ & \begin{tabular}{|c} 
Protocolo \\
de \\
actuación \\
ante \\
eventos de \\
crisis
\end{tabular} \\
\hline Recuperación & $\begin{array}{l}\text { Evaluación, } \\
\text { control y } \\
\text { retroalimenta- } \\
\text { ción }\end{array}$ & $\begin{array}{l}\text { Evaluación } \\
\text { de daños y } \\
\text { perjuicios }\end{array}$ & $\begin{array}{l}\text { Trabajo de } \\
\text { terreno, } \\
\text { observa- } \\
\text { ción y } \\
\text { cuantifi- } \\
\text { cación }\end{array}$ & $\begin{array}{c}\text { Comisión } \\
\text { de evalua- } \\
\text { ción de } \\
\text { daños y } \\
\text { perjuicios }\end{array}$ & $\begin{array}{l}\text { Después } \\
\text { del evento } \\
\text { de crisis }\end{array}$ & \begin{tabular}{|l} 
Empresa \\
y su \\
entorno \\
de \\
responsa- \\
bilidad
\end{tabular} & $\begin{array}{c}\text { Manual de } \\
\text { evaluación } \\
\text { de daños y } \\
\text { perjuicios }\end{array}$ \\
\hline
\end{tabular}

Manejo correctivo/preventivo de los riesgos e impactos para la Gestión de Crisis en el Turismo.

Para el manejo de impactos se propone la estructuración del sistema de medidas de gestión basado en los siguientes planes y programas que 
cubren el control de impactos potencias e impactos reales:

- $\quad$ Plan de medidas de mitigación: para eliminar, reducir y modificar la condición de los impactos generados por los riesgos y evento de crisis.

- Plan de medidas de compensación: para mejorar, restaurar, remplazar y retribuir los impactos generados por los riesgos y eventos de crisis.

- Plan de manejo para impactos residuales: para efectos que persisten de forma total o parcial después de haber sido aplicadas las medidas correctoras, tales como impactos accidentales causados por eventos excepcionales o situaciones de riesgo prevaleciente, así como aquellos impactos que pueden presentarse sin haber sido previstos.

- Programa de concientización para la aceptación de los impactos: para lograr la aceptación social de los impactos generados por riesgos y eventos de crisis, propiciando la comprensión, cambio de opinión y transformación de actitudes y prácticas.

- Programa de monitoreo para el control de impactos: proporcionar información para documentar los impactos, advertir cambios no previstos y obtener información sobre valores críticos que podrían alcanzar las variables objeto de monitoreo. Debe considerar variable a medir; escalas territoriales y puntos de monitoreo; escalas temporales y frecuencia; métodos, procedimientos y técnicas; y modalidades de comunicación y de introducción de los resultados.

- $\quad$ Programa de auditoría para el control de impactos: para proveer información a la autoridad de decisión relativa a cuestiones de interés que pueden ser incluidas en las inspecciones y auditorías ordinarias de riesgos y fenómenos de crisis.

\section{Conclusión}

La revisión de la literatura utilizada como referente para el aprendizaje permitió la comprensión y operacionalización de las variables conceptuales objeto de estudio -riesgo y crisis- desde una perspectiva dinámica, la identificación de las limitaciones para el tratamiento integrado de los riesgos y crisis a nivel de destinos y organizaciones turísticas, así como la interpretación del impacto experimentado durante la ocurrencia de diferentes tipos de eventos catastróficos, lo que posibilitó advertir la conveniencia de alcanzar una conveniente planificación y preparación para la gestión preventiva y proactiva de riesgos/eventos de crisis en el turismo.

Como parte del análisis de la teoría explicativa para la implementación en un caso de estudio la literatura aportó una valiosa información que sirvió de base a la conformación del enfoque metodológico que sustenta el modelo de las 4 “Rs” según enfoques y procedimientos 
validados por diversos autores e instituciones, destacando en todos los casos la complejidad para encontrar soluciones orientadas a una óptima gestión holística de riesgos $\mathrm{y}$ crisis en el turismo, lo cual se relaciona mayoritariamente con la dificultad que representa superar las percepciones negativas con respecto a estas, particularmente en casos de inseguridad, insalubridad y deterioro en las condiciones de bienestar.

Se reconoce el valor imprescindible de disponer de información confiable, procesos de comunicación efectiva y acceso a recursos materiales $\mathrm{y}$ financieros para responder de forma efectiva ante riesgos y eventos de crisis, al tiempo que se coincide en la necesidad de realizar en forma sistemática la evaluación de la efectividad de los sistemas de gestión de riesgos y crisis, lo cual permitirá a los destinos y organizaciones estar preparados una vez que se enfrenten a eventos catastróficos.

La metodología implementada resultó válida para el estudio, ya que los diferentes participantes fueron capaces de aportar apreciable información a partir del conocimiento fáctico de que son portadores, el cual está sustentado en la experiencia de haber estado expuestos a situaciones de riesgos y eventos de crisis en las que han sido partícipes de forma directa y/o indirecta. Esto demuestra la contribución de las comunidades a los procesos de toma de decisiones, toda vez que son conocedores de la realidad en que viven, lo que permite una actuación más participativa y menos tecnocrática, factor que puede incidir positiva o negativamente sobre las percepciones, reducción, preparación y respuesta ante los problemas de inseguridad que afectan el turismo en la ciudad.

Para promover la planificación y preparación sistemática e integrada del proceso de gestión sustentable de riesgos y crisis en el turismo mexicano será necesario transitar desde el escenario actual caracterizado predominantemente por los enfoques reactivos - correctivos a las proactivos preventivos, los cuales deberán estar orientados hacia un escenario de sustentabilidad en el que se integre mediante una triada estratégica el tratamiento totalizador a las dimensiones económica, ambiental y social.

Hasta el presente la problemática de la planificación y preparación para la gestión de riesgos y eventos de crisis en el turismo de México no se ha convertido en una prioridad estratégica para la SECTUR y otras instancias de decisión, en tanto la focalización ha estado orientada parcialmente hacia el turista como sujeto agente del viaje. Explícitamente la gestión integrada de riesgos y crisis en el turismo no aparece como una prioridad dentro de las líneas de interés para la investigación, ni para la formación y capacitación, a pesar de que algunas instituciones educativas y de investigación abordan el tema de según refleja la producción científica publicada. Estas premisas justifican la necesidad de posicionar de forma institucionalizada el proceso de gestión integrada de riesgos y crisis en el turismo mexicano como 
problema estratégico con el fin de generar soluciones efectivas en diferentes horizontes espacio-temporales de gestión.

Con respecto a las bases institucionales para la gestión de riesgos y crisis en el turismo mexicano se comprueba que existen diferentes documentos normativos e institucionales, pero se carece de bases procedimentales específicas e instrumentos que permitan la gestión de los eventos de riesgos y crisis por parte de cada sujeto implicado, además se aprecia falta de alineación horizontal entre las diferentes instituciones y organismos encargados de la gestión, de forma tal que se logre un enfoque holístico y más innovador. Están identificadas las funciones básicas de la Administración Pública Federal, estatal y municipal, así como los órganos de consulta y coordinación, e instrumentos financieros, pero la información que se maneja entre las diferentes entidades de gestión es muy heterogénea, por lo que es difícil encontrar puntos de enlace y coincidencia que sirvan de base a la actuación coordinada y estratégica en respuesta ante eventos de crisis que puedan afectar los diversos sectores de la sociedad y la economía.

La construcción participativa de un plan para la gestión de riesgos y crisis en el turismo de Ciudad Juárez utilizando el modelo de las 4 "R" demuestra una favorable factibilidad de implementación para la actuación ante eventos provocados por situaciones de inseguridad, lo que permitirá promover una mejor coordinación entre el sector turístico y las organizaciones públicas/privadas encargadas de la atención a riesgos y crisis, de manera que se minimicen los impactos sobre en el bienestar social, económico y ambiental del destino y sus organizaciones. Será oportuno el tratamiento posterior de otros tipos de riesgos y eventos de crisis utilizando este mismo enfoque metodológico, con el fin de consolidar un sistema integrado de manejo de los efectos adversos generados por eventos que representan diferentes niveles de peligro según condiciones de respuesta instituidas en la ciudad.

En correspondencia con la revisión documental y programática se comprueba que no existe en el destino Ciudad Juárez un sistema integrado para prevenir y responder a los peligros de la delincuencia, la seguridad y la salud relacionados con el turismo. No se cuenta a nivel local con una Organización de Gestión de Destinos /OGD/ que facilite la proyección y seguimiento de la planificación del proceso de gestión de riesgos y crisis en el turismo, así como la implementación de un modelo de intervención factible con procedimientos específicos para la actuación ante cada evento que pueda impactar negativamente sobre las actividades del sector. Las respuestas ante situaciones de riesgos y crisis han sido frecuentemente de carácter correctivo, a pesar de que la mayoría de las organizaciones cuentan con instrumentos de actuación en casos de catástrofes y emergencias. El rasgo recurrente que se advierte y que permite ser identificado como 
regularidad es la dificultad que representa superar las percepciones negativas relativas a la seguridad en la ciudad.

Ciudad Juárez no dispone de un modelo operativo de seguridad, asistencia y protección integral para la gestión de riesgos y eventos de crisis a nivel de destino que implique de manera coherente los diferentes componentes y actores del sistema de turismo local. Es insuficiente el desarrollo de los mecanismos permanentes de vinculación, colaboración y coordinación de acciones gubernamentales e interinstitucionales para desarrollar programas de atención integral a la preservación de los atractivos turísticos, al turista, a las empresas y a la comunidad anfitriona.

De igual forma, es limitada la información sobre riesgos y eventos de crisis que favorezcan una experiencia más confiable con altos estándares de seguridad y calidad en el destino, careciéndose de mecanismos eficientes de auxilio y asistencia turística en las zonas de mayor afluencia de visitantes, y de protocolos efectivos para la implementación en casos de contingencias que afecten los intereses del turismo en la ciudad.

La posible solución estratégica del problema estudiado debería estar fundamentada en la integración entre el turismo y la gestión de riesgos y crisis provocadas por situaciones de inseguridad de manera sistemática y eficiente. Para ello deberá considerarse como referente la oportunidad latente para proyectar soluciones estratégicas participativas frente a la manifestación de riesgos y crisis en el turismo a través del fortalecimiento de la planificación y preparación de los diferentes actores implicados.

Se comprueba que el enfoque integrador utilizado para la planificación y preparación del proceso de gestión de riesgos y crisis en el turismo es un valioso instrumento para contribuir al manejo de los impactos provocados por eventos de inseguridad a nivel del destino y sus organizaciones, lo cual permitirá reducir afectaciones y/o pérdidas humanas, materiales y financieras en el mediano y largo plazo. En tal sentido, queda validado en la práctica la utilidad del instrumento construido para el estudio y denominado cadena riesgo de daño o perjuicio - evento de crisis situación de crisis - exposición y actuación - efectos - resiliencia; la misma relaciona el riesgo de daño o peligro según amenaza provocada por eventos de inseguridad y los niveles de vulnerabilidad de los componentes del sistema de turismo con respecto al evento de crisis según peligros potenciales que representa para cada uno de los receptores expuestos a los impactos que se derivan para la salud, bienestar y seguridad de las poblaciones afectadas, las cuales deberán resistir, absorber, adaptarse y recuperarse de los efectos recibidos en los tiempos previstos y con los recursos disponibles. 


\section{References:}

Aktas, G. y Gunlu, E. A. 2005. Crisis management in tourist destinations. Global Tourism ( $3^{\mathrm{a}}$ Ed.). W. F. Theobald (Editor): 440-457, Amsterdam, Elsevier.

Centro Nacional de Prevención de Desastres. 2007. Características e Impacto Socioeconómico de los principales desastres ocurridos en la República Mexicana en el año 2007. México: CENAPRED.

Comité Consultivo Público Conjunto /CCPC/ de la Comisión para la Cooperación Ambiental /CCA/. 2015. Soluciones sustentables para mitigar los efectos de las aguas pluviales. Comunicado de prensa. 15 de julio de 2015 http://us7.campaignarchive2.com/?u=5fa638f92a1d9b74dd1d595b81\&id=871f6800dc\&e=28510a 2374 [recuperado 15 de julio de 2015].

Cutter, Susan L. and colleagues. 2015. Pool knowledge to stem losses from disasters. Public awareness, rigorous risk research and aligned targets will help policy-makers to increase resilience against natural hazards. Nature. Vol 522. 18 June 2015. Macmillan Publishers Limited.

De Sausmarez, N. 2004. Crisis Management for the Tourism Sector: Preliminary Considerations in Policy Development. Tourism and Hospitality Planning \& Development, 1 (2), pp. 157-172.

De Sausmarez, N. 2007. The potential for tourism in post-crisis recovery: lessons from Malaysia's experience of the Asian financial crisis. Asia Pacific Business Review, April 13 (2), pp. 277-299.

Faulkner, B. 2001. Towards a framework for tourism disaster management. Tourism Management, 22 (2), pp. 135-147.

Figueroa, M. 2014. Juárez desciende a posición 37 en lista de ciudades más violentas. El Diario de Juárez. 15 de enero de 2014. http://diario.mx/ [recuperado el 21 de marzo de 2015].

Frisby, E. 2002. Communicating in a crisis: The British Tourist Authority's responses to the foot-and-mouth outbreak and $11^{\text {th }}$ September, 2001. Journal of Vacation Marketing, 9 (1), pp. 89 -100.

Gallegos, R. 2013. Hace Segob declaratoria de emergencia por nevadas en Chihuahua. EL Diario de Juárez. 17 de enero de 2013. http://diario.mx/ [recuperado el 21 de marzo de 2015].

González, Manuel. 2010. Gestión Ambiental en el Turismo y la Hostelería. Editorial CEP S.L. Madrid, España.

González, Manuel; y Maury Fernández. 2007. Gestión preventiva de los impactos del Huracán Wilma sobre el turismo: Zona Hotelera Insular de Caibarién, Cuba Central. Teoría y Praxis. 4 (2007: 67-88). México.

González, S. 2009. Influenza desploma el turismo. 02 de mayo de 2009. La Jornada. http://www.jornada.unam.mx/ultimas [recuperado el 11 de mayo de 2015]. 
Henderson, J.C. 2007. Tourism Crises: Causes, Consequences and Management. Amsterdam, Butterworth-Heinemann.

Institute for Economics \& Peace /IEP/. 2015. Global Peace Index. Measuring Peace, its Causes and its Economic Value. Sydney, New York and Mexico City. PDF. www.economicsandpeace.org.

Kim, J.E., \& Pennington-Gray, L. 2012. Corporate Social Responsibility and Ethics in the Tourism Industry: Using a Survey of Managers. The Journal of American Academy of Business, Cambridge, 17(2).

Mitroff, I.; Pearson, C. M. y Harrison, L. K. 2002. Cómo gestionar una crisis. Barcelona, Ediciones Gestión 2000.

Morales Cárdenas, Sara; Marisol Rodríguez Sosa; Erick Sánchez Flores. 2013. Seguridad urbana y vulnerabilidad social en Ciudad Juárez. Un modelo desde la perspectiva de análisis espacial. Frontera Norte, Vol. 25, Núm. 49, enero -junio de 2013. P. 29 - 56.

Organización Mundial del Turismo /OMT/. 2011. Integración del turismo y la gestión de emergencias. http://media.unwto.org/es/news/2011-1020/integracion-del-turismo-y-la-gestion-de-emergencias [Consultado el 22 de octubre de 2013].

Palafox, Alejandro; y Alejandra Gutiérrez. 2013. Cambio climático y desarrollo turístico. Efecto de los huracanes en Cozumel, Quintana Roo y San Blas, Nayarit. Investigación y Ciencia de la Universidad Autónoma de Aguascalientes. Número 58, (44-54) Mayo-Agosto 2013. México.

Palafox, Alejandro; y Oscar Frausto /coords/. 2008. Turismo, Desastres Naturales y Medio Ambiente. Universidad de Quintana Roo. México.

Pennington-Gray, L., Kaplanidou, K., \& Schroeder, A. 2012. Drivers of Social Media Use among African Americans in the Event of a Crisis. Natural Hazards. DOI: 10.1007/s11069-012-0101-0 Online First (February 6).

Pennington-Gray, L., Schroeder, A., \& Kaplanidou, K. 2011. Examining the Influence of Past Travel Experience, General Web Searching Behaviors and Risk Perceptions on Future Travel Intentions. International Journal of Safety and Security in Hospitality and Tourism, 1(1), 64-92.

Ritchie, J. R. B. y Crouch, G. I. 2003. The competitive destination: A sustainable tourism perspective, Wallingford, UK, CABI Publishing.

Rodríguez-Toubes Muñiz, Diego. 2011. Gestión proactiva de crisis en el turismo: una experiencia de estudio en Galicia. PASOS. Revista de Turismo y Patrimonio Cultural. Vol. 9 No 2 págs. 279-289.

Rodríguez-Toubes Muñiz, Diego; y José Antonio Fraiz Brea. 2010. Gestión de crisis en el turismo: la cara emergente de la sostenibilidad. Encontros científicos - tourism \& management studies Nr. 6. págs. 49-58.

Rosengaus, M., Jiménez, M., \& Vázquez, M. 2014. Atlas Climatológico de Ciclones Tropicales en México. México, D.F.

Vallejo, J. 2013. Declara Gobernación emergencia en Juárez y Chihuahua 
por inundaciones. El Diario De Juárez. 16 de septiembre de 2013 http://diario.mx/ [recuperado el 21 de marzo de 2015].

Villegas, J., Matyas, C., Srinivasan, S, Cahyanto, I., Thapa, B. \& Pennington-Gray, L. 2012. Florida Tourists' Individual Traits and their Influence on Affect, Risk Perception, and Likelihood of Evacuation after Exposure to Hurricane Warning Messages. Natural Hazards. DOI: 10.1007/s11069-012-0119-3 Online First (March 9).

Wilks, J. y Moore, S. 2003. Tourism Risk Management for the Asia Pacific Region: An Authoritative Guide for Managing Crises and Disasters. Commonwealth of Australia, APEC International Centre for Sustainable Tourism (AICST). 